Document downloaded from:

http://hdl.handle.net/10251/101855

This paper must be cited as:

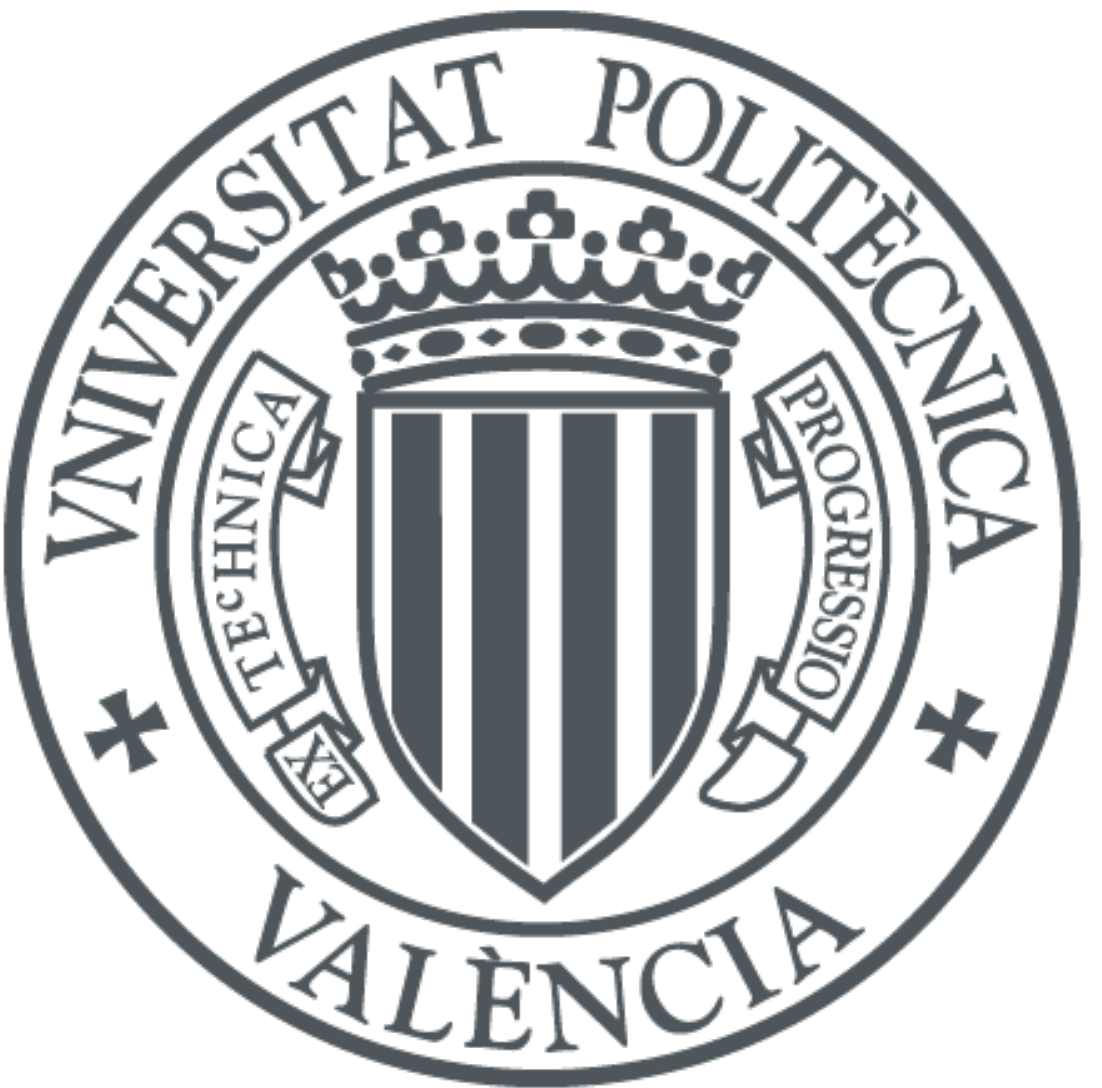

The final publication is available at

https://doi.org/10.1016/j.fuel.2016.12.013

Copyright Elsevier

Additional Information 


\title{
Investigation of Late-Cycle Soot Oxidation Using Laser Extinction and In-Cylinder Gas Sampling at Varying Inlet Oxygen Concentrations in Diesel Engines
}

\author{
Yann Gallo ${ }^{\mathrm{a}}$, Ville Berg ${ }^{\mathrm{b}}$, Johan Simonsson ${ }^{\mathrm{c}}$, Erik Svensson ${ }^{\mathrm{a}}$, MengQin Shen ${ }^{\mathrm{a}}$, Per-Erik \\ Bengtsson $^{\mathrm{c}}$, Joakim Pagels ${ }^{\mathrm{b}}$, Martin Tunér ${ }^{\mathrm{a}}$, Antonio Garcia ${ }^{\mathrm{d}}$, Öivind Andersson ${ }^{\mathrm{a}}$
}

${ }^{\text {a }}$ Division of Combustion Engines, Lund University, Sweden

${ }^{\mathrm{b}}$ Division of Ergonomics and Aerosol Technology, Lund University, Sweden

${ }^{c}$ Division of Combustion Physics, Lund University, Sweden

${ }^{\mathrm{d}}$ CMT Motores Térmicos, Universitat Politécnica de Valencia, Spain

\begin{abstract}
This study focuses on the relative importance of $\mathrm{O}_{2}$ and $\mathrm{OH}$ as oxidizers of soot during the late cycle in diesel engines. Laser-extinction measurements of soot oxidation rates are made in an optically accessible engine. These are combined with in-cylinder gas sampling data from a single-cylinder engine fitted with a fast gas sampling valve. Both measurements confirm that the in-cylinder soot oxidation slows down when the inlet concentration of $\mathrm{O}_{2}$ is reduced. A $50 \%$ decrease in intake $\mathrm{O}_{2}$ concentration reduces the soot oxidation rate by $600 \%$, a discrepancy indicating that $\mathrm{O}_{2}$ in itself is not the main soot oxidizing species. Chemical kinetics simulations of $\mathrm{OH}$ concentrations in the oxidation zone and estimates of the $\mathrm{OH}$-soot oxidation rate point towards $\mathrm{OH}$ being the dominant oxidizer.
\end{abstract}

\section{Introduction}

Diesel engines are favored by high efficiencies but are challenged by high emissions of nitrous oxides $\left(\mathrm{NO}_{\mathrm{x}}\right)$ and particulate matter $(\mathrm{PM})$, if not coupled with adequate exhaust aftertreatment technologies such as $\mathrm{NO}_{\mathrm{x}}$ adsorbers and diesel particulate filters (DPF). Diluting the charge by Exhaust Gas Recirculation (EGR) is a widespread method for reducing the $\mathrm{NO}_{\mathrm{x}}$ emissions by decreasing the combustion temperature. On the other hand, EGR 
generally increases PM emissions due to deteriorating in-cylinder soot oxidation rates $[1,2]$. Previous studies indicate that, under most conditions applicable to diesel engines, this oxidation has a dominating influence on the soot emission levels [2-4].

EGR reduces the intake oxygen concentration. This has a number of potential effects on the soot oxidation process. First, it will decrease the availability of oxygen during the late cycle, which could limit the oxidation rate. It also lowers the flame temperature, slowing the chemical kinetics of the oxidation process as well as decreasing the formation of hydroxyl radicals $(\mathrm{OH})$ [5], which is believed to be the main oxidizing species [6-10].

The purpose of this study to cast light on the relative importance of $\mathrm{O}_{2}$ and $\mathrm{OH}$ as soot oxidizers during the late cycle. It is based on data from optical measurements and in-cylinder gas sampling. The optical measurements are made using laser extinction in an optically accessible single-cylinder engine fitted with a Bowditch-type piston extender [11]. The gas sampling data are acquired from a single-cylinder engine without optical access, fitted with a fast gas sampling valve. The analysis is complemented with a simulation of $\mathrm{OH}$ availability in the flame using a zero-dimensional (0-D) reactor model.

\section{Experimental facilities}

\section{Engine Setup}

The engine used for the optical study is a heavy-duty direct-injection diesel engine based on a Scania D12, operated as a single-cylinder engine. A single-cylinder version of a Scania D13 is used for the in-cylinder gas sampling measurements. These engines are henceforth referred to as the optical and the all-metal engine. In order to produce as similar conditions as possible, both configurations employ the same cylinder head and the same injector. A Scania XPI 
common-rail fuel injection system capable of fuel pressures up to 2500 bar is used. The injector is a stock item with eight nozzle holes. The fuel used is Swedish MK1 diesel. Specifications of the engines, fuel system and fuel are given in Table 1.

\section{Table 1.}

\section{Engine and fuel specifications}

\begin{tabular}{|c|c|c|}
\hline Engine base type & Scania D12 DI diesel & Scania D13 DI diesel \\
\hline Bore & $127 \mathrm{~mm}$ & $130 \mathrm{~mm}$ \\
\hline Stroke & $154 \mathrm{~mm}$ & $160 \mathrm{~mm}$ \\
\hline Comp. Ratio & 15.6 & 16 \\
\hline Swirl & \multicolumn{2}{|c|}{1.6} \\
\hline Displacement & 1.951 & 2.121 \\
\hline EGR & External & Internal \\
\hline Injection system & \multicolumn{2}{|c|}{ XPI common rail } \\
\hline Nozzle flow number & \multicolumn{2}{|c|}{$207 \mathrm{pph}$} \\
\hline Number of holes & \multicolumn{2}{|c|}{8} \\
\hline Firedeck angle & \multicolumn{2}{|c|}{$17^{\circ}$} \\
\hline Hole diameter & \multicolumn{2}{|c|}{$0.175 \mathrm{~mm}$} \\
\hline Fuel type & \multicolumn{2}{|c|}{ MK1 Diesel } \\
\hline Cetane number & \multicolumn{2}{|c|}{51} \\
\hline Density & \multicolumn{2}{|c|}{$815 \mathrm{~kg} / \mathrm{m}^{3}$} \\
\hline Lower Heating Value & \multicolumn{2}{|c|}{$42.9 \mathrm{MJ} / \mathrm{kg}$} \\
\hline $\mathrm{C} / \mathrm{H}$ & \multicolumn{2}{|c|}{0.53} \\
\hline
\end{tabular}

The two setups use different sources of EGR. On the optical engine, exhaust gases are produced using a diesel furnace operating at stoichiometric conditions. These are mixed with fresh air, heated and compressed to the desired inlet conditions in order to achieve a stable external source of "EGR". On the all-metal engine, exhaust gases are taken from the exhaust manifold and fed to the intake manifold, using flow and back-pressure valves to control the flow. The intake $\mathrm{O}_{2}$ concentration is used to measure the EGR rate. In the optical engine, it is measured during engine operation without injection by a lambda sensor located in the exhaust. For the all-metal engine, the concentration of inlet $\mathrm{O}_{2}$ is calculated as:

$$
O_{2, \text { in }}=\frac{C O_{2, \text { in }}}{C O_{2, e x}}\left(O_{2, e x}-O_{2, a m b}\right)+O_{2, a m b}
$$


where $O_{2, e x}$ is the exhaust $\mathrm{O}_{2}$ concentration measured by a lambda sensor, $O_{2, a m b}$ is the ambient $\mathrm{O}_{2}$ concentration set at 20.95\%. $\mathrm{CO}_{2, \text { in }}$ and $\mathrm{CO}_{2, \text { ex }}$ are the $\mathrm{CO}_{2}$ concentrations of inlet and exhaust both measured using an infrared detector in an AVL AMA i60 emission system.

Another difference between the setups is the shape of the piston bowl. In the D12 engine, the bottom of the bowl is flat in order to facilitate the optical access, while the D13 engine has a slightly conical bowl bottom. As shown in Figure 1, both configurations had open combustion chambers. While the differences should give rise to some differences in the gas motion, the overall trends in the oxidation process are expected to be highly comparable between the engines.

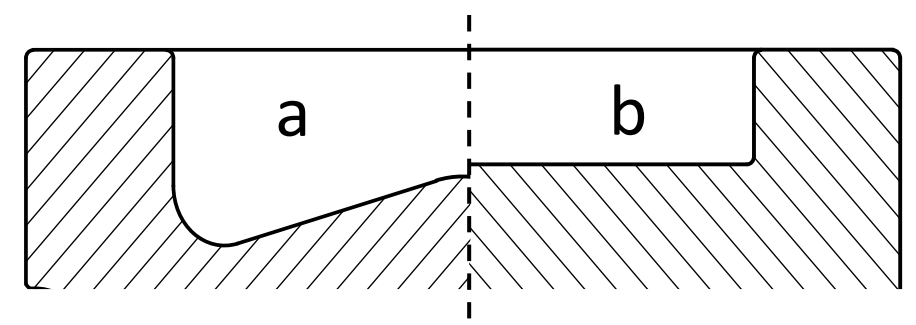

Figure 1.

Profile of the metal piston used in the D13 engine (a) and of the quartz piston used in the D12 engine (b).

\section{Operating conditions}

The engines are operated at a speed of $1200 \mathrm{rpm}$ and a load of 6 bar IMEP. The EGR rate is varied in order to obtain various inlet $\mathrm{O}_{2}$ concentrations $(13 \%, 15 \%$ and $21 \%)$. The cylinder pressure is monitored using a side-mounted Kistler $6125 \mathrm{C}$ transducer coupled to a Kistler 5011B10 charge amplifier. A crank angle encoder giving 1800 pulses per revolution is used, resulting in one pulse per $0.2 \mathrm{CAD}$. The injection pressure is kept constant as well as the 
duration of injection $(650 \mu \mathrm{s})$. The start of injection is adjusted in order to maintain CA50 at approximately 9 CAD ATDC. A summary of the operating conditions is given in Table 2.

\section{Table 2.}

\section{Engines operating conditions}

\begin{tabular}{|l|c|c|}
\hline \multicolumn{2}{|c|}{ Operating conditions } \\
\hline Engine & Scania D12 DI diesel & Scania D13 DI diesel \\
\hline Speed & \multicolumn{2}{|c|}{$1200 \mathrm{rpm}$} \\
\hline Load & \multicolumn{2}{|c|}{ bar IMEPg } \\
\hline Pinj & \multicolumn{2}{|c|}{ 8 CAD ATDC } \\
\hline CA50 & Adjusted to keep CA50 constant \\
\hline SOI & 650 $\mu$ s \\
\hline DOI & 1.8 bar \\
\hline Inlet P & \multicolumn{2}{|c|}{$70^{\circ} \mathrm{C}$} \\
\hline Inlet T & \multicolumn{2}{|c|}{ MK1 Swedish Diesel bar } \\
\hline Fuel & \multicolumn{2}{|c|}{ Variable $\left(13 \%\right.$ to $\left.21 \% \mathrm{O}_{2}\right)$} \\
\hline EGR rate &
\end{tabular}

In order to compensate for the difference in compression ratio, the top dead center (TDC) conditions in temperature and density are matched between the engines. This is realized by applying adiabatic compression calculations, leading to the use of a substantially lower inlet pressure on the all-metal engine. A sample motored pressure trace at $15 \%$ inlet $\mathrm{O}_{2}$ from the optical engine is compared with a motored one from the all-metal engine without EGR in Figure 2a. The apparent heat release rate (AHRR) from a case with combustion at $15 \% \mathrm{O}_{2}$ is shown in Figure $2 b$ for the two engines. The differences in thermodynamic conditions at TDC and during combustion are minor, justifying the validity of the comparison between setups. 


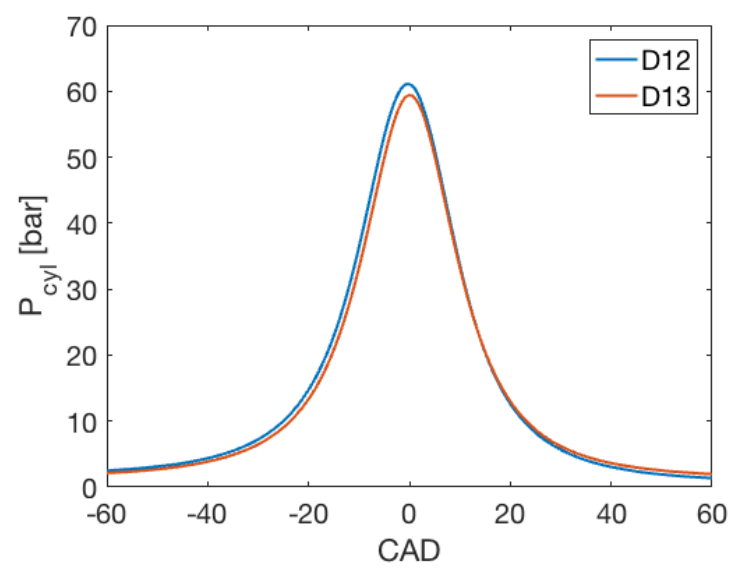

Figure $2 a$.

Sample motored trace for the $15 \%\left[\mathrm{O}_{2}\right]$ case. The D13 trace (all-metal engine) is recorded without EGR.

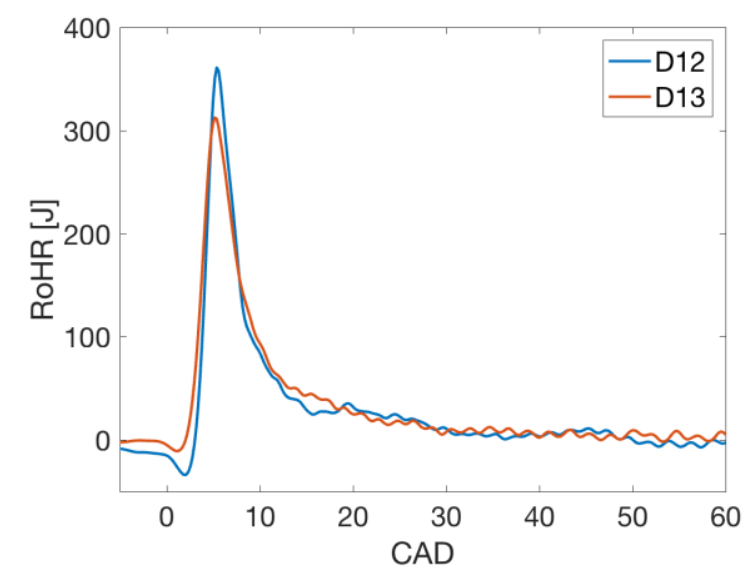

Figure $2 b$.

Sample AHRR for the $15 \%\left[\mathrm{O}_{2}\right]$ case.

\section{Soot measurement techniques}

\section{Laser extinction method}

The laser extinction technique is a quantitative measurement technique for soot that has been applied successfully in combustion engines for several decades $[2,3,12-14]$ as well as in spray vessels [15-17]. The intensity of a laser beam decreases as it passes an absorbing medium, e.g. containing soot. The initial and transmitted intensities, $I_{0}$ and $I$, are measured 
and, assuming that the in-cylinder combustion medium is optically thin, the Beer-Lambert law applies:

$$
I=I_{0} e^{-K L}
$$

Here, $K$ is the extinction coefficient and $L$ is the length of the absorbing medium, in this case the vertical extent of the combustion chamber. Extinction is any process that decreases the initial laser intensity, and is thus a combination of absorption and scattering of light out of the beam path. In the Rayleigh limit, where the particle sizes are much smaller than the laser wavelength, the scattering is assumed to be negligible and $K$ is then the absorption coefficient [18]. Under this assumption, $K$ can be related to the soot volume fraction, $f_{v}$, as

$$
K=\frac{f_{v} 6 \pi E(m)}{\lambda}
$$

where $\lambda$ is the laser wavelength. $E(m)$ is the refractive index function, representing the imaginary part of $\left(m^{2}-1\right) /\left(m^{2}+2\right)$, where $m$ is the complex refractive index of the soot particles, see e.g. [19]. Throughout this paper, the soot concentration is represented by the product $K L$, which is directly related to the average soot concentration in the beam path and obtained directly from the relative transmission measurement. This product thus remains constant if the soot content in the beam path remains constant, even if the piston moves. A decrease in $K L$ after the end of injection (EOI) can thereby be attributed to net oxidation of the soot in the cylinder. 


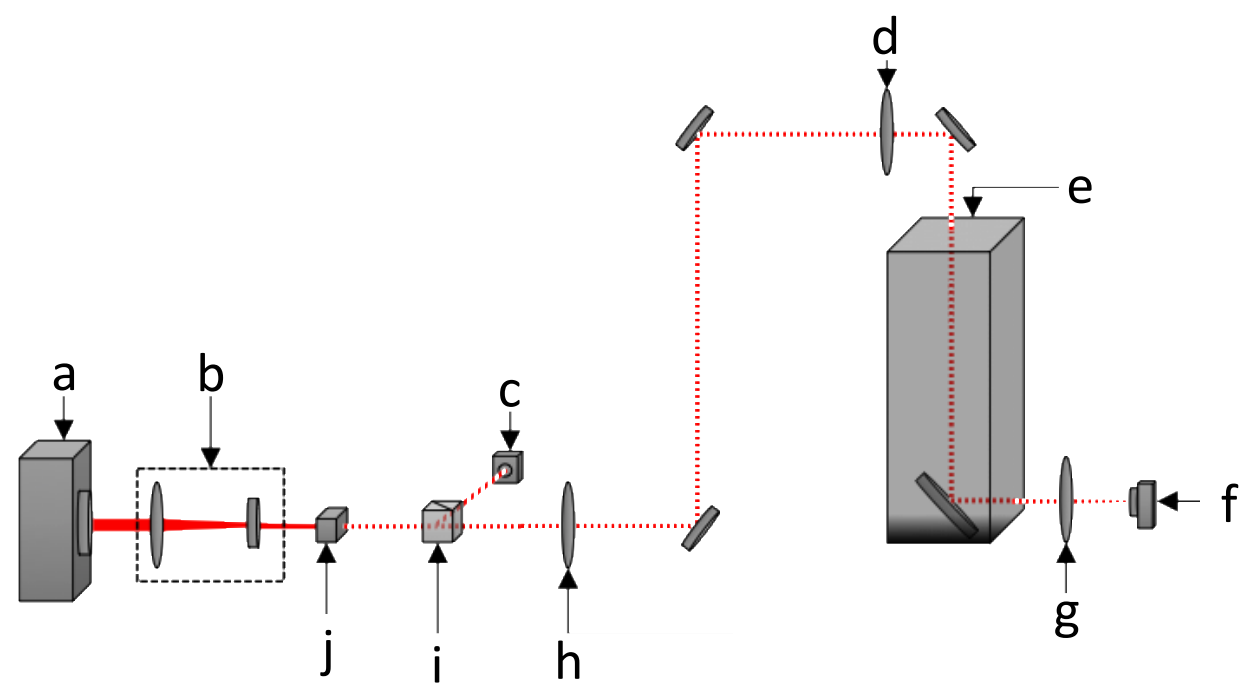

Figure 3.

The parts of the laser extinction setup. Diode laser (a), telescope lenses (b), photodiode for the reference signal (c), re-collimation lens $(d)$, engine (e), photodiode $(f)$, collection lens $(g)$, re-collimation lens ( $h$ ), beamsplitter (i), and acousto-optic modulator, or AOM $(j)$.

A schematic representation of the setup is shown in Figure 3. The Bowditch piston extension has a full quartz piston top and a $45^{\circ}$ mirror in a fixed position below it. An insert containing an angled window is used in place of one of the exhaust valves, providing optical access from the top of the cylinder. The angle of the window compensates for the angle of the insert and makes it possible to obtain a vertical beam path through the cylinder. A cross-section of this optical access is given in Figure 4. The absence of one exhaust valve does not substantially affect the combustion process since the engine is running at a relatively low speed of 1200 rpm, allowing for effective gas scavenging. A more detailed presentation of the setup can be found in [2]. 


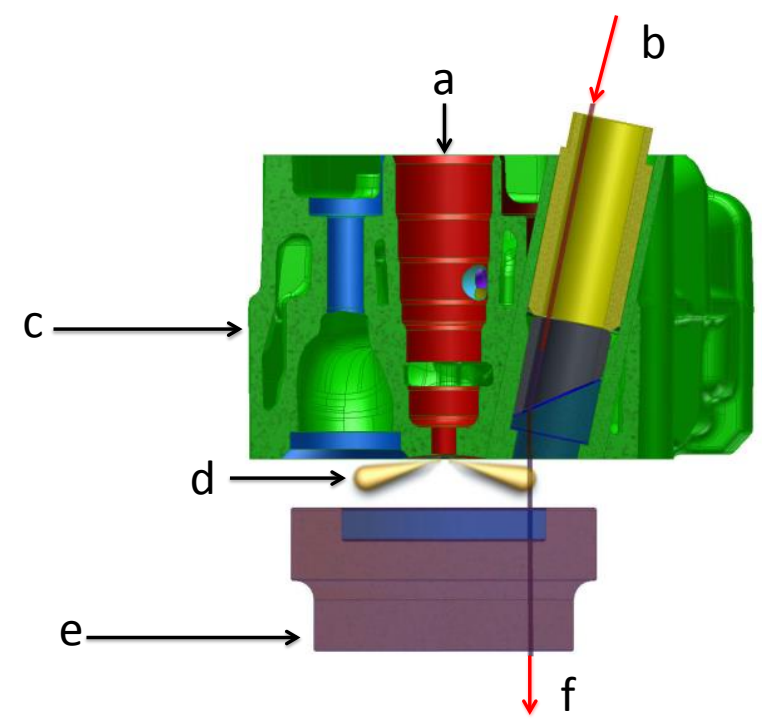

Figure 4.

Section through the cylinder head used in the extinction setup. Injector location (a), laser entrance (b), cylinderhead (c), burning sprays (d), optical piston (e), and laser exit (f).

\section{In-cylinder gas sampling}

In-cylinder gas sampling was performed on the all-metal engine, fitted with the same cylinder head as used in the optical measurements. In the all-metal engine, the quartz window in the insert (yellow detail in Figure 4) was replaced with a fast-acting gas sampling valve [20]. During operation, a solenoid hammer actuates the valve by hitting the top of the valve stem, rendering the start of sampling and the sampled flow rate controllable. The valve driver is controlled by a TTM signal from a computer program and triggered on crank angle basis. With these features the gas flow through the valve can be controlled in a wide range, with respect to sampling timing, sampling rate, etc. In this study, the gas flow was kept constant at 1 liter per minute (at ambient atmospheric pressure and temperature) for each sampling point. This volume corresponds to approximately $0.05 \%$ of the total cylinder volume. With this flow rate, the minimum step-by-step resolution for the sampling timing can be less than 3.5 crank angle degrees CAD at high in-cylinder pressures [21]. 
Figure 5 presents the dilution and gas analyzing system. The gases are diluted with nitrogen $\left(\mathrm{N}_{2}\right)$ during the first step (D1) in order to prevent further oxidation of the particles. The following steps (D2 and D3) reduce the amount of particles to a level suitable for the aethalometer (Magee Scientific AE33), which measures the Black Carbon (BC) concentration. $\mathrm{BC}$ is the part of the particle matter that effectively absorbs light, i.e. the soot. The latter is used for on-line chemical particle analysis [22].

The aethalometer is based on the absorption of laser light by the probed particles. Seven different wavelengths are used, ranging from $370 \mathrm{~nm}$ to $950 \mathrm{~nm}$. These allow determination of the optical properties of the soot particles. In this study, the BC concentration is obtained as the average of the measurements at the two highest wavelengths $(880 \mathrm{~nm}$ and $950 \mathrm{~nm})$ in order to reduce interferences from organics or polycyclic aromatic hydrocarbons (PAHs) that absorb in and near the ultraviolet region [20].

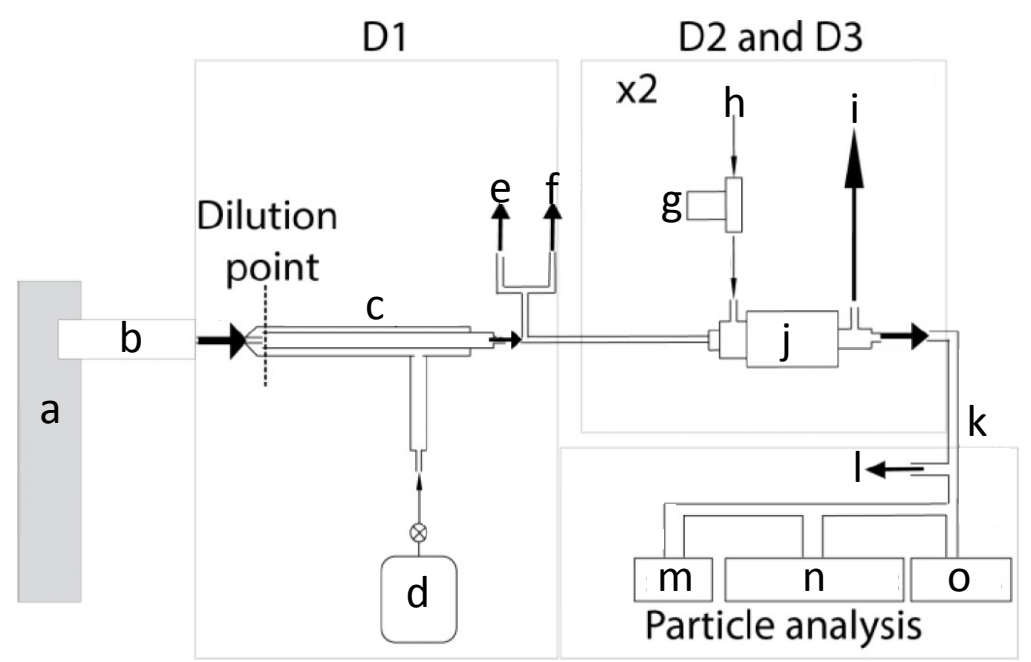

Figure 5.

Diagram of dilution and gas analyzing system [20]. D1, D2 and D3 are dilution steps. Engine (a), fast sampling valve (b), dilution probe (c), $N_{2}$ bottle (d), $N O_{x} / C O(e)$, flow reading $(f)$, 
pressure regulator $(g)$, air $(h)$, diluted sample ( $i$, not used), ejector diluter $(j)$, diluted sample (k), NOx/CO (l), SMPS (m, not used in this article), aethalometer (n). and SP-AMS (o, not used in this study).

\section{Simulation tools}

The availability of $\mathrm{OH}$ in the flame is evaluated using a $\Phi-T$ map, a concept first introduced by Kamimoto et al [23]. The $\Phi-T$ map of $\mathrm{OH}$ mass fraction is constructed using a 0 -D reactor, from LOGEsoft [24], with constant pressure, temperature and equivalence ratio. The MK1 Diesel was modeled by a surrogate fuel with 70 percent $n$-heptane together with 30 percent toluene. Lars Seidel's chemical mechanism for $n$-heptane could then be applied in the simulations [25]. The addition of toluene is used to mimic the sooting behavior of diesel, which $n$-heptane alone cannot. Such surrogate for diesel fuel has been commonly used in diesel combustion studies [26,27] and ascertained in [28]. The map consists of a grid of nodes at different $\Phi$ and $T$ conditions (the pressure is constant for all nodes). One simulation is performed at every node and the $\Phi-T$ map shows the $\mathrm{OH}$ yield after 2 milliseconds.

\section{Dependency of the soot oxidation rate on $\mathrm{O}_{2}$ and $\mathrm{OH}$ availability}

Gallo et al. observed a constant degradation of the soot oxidation rate with reduced intake $\mathrm{O}_{2}$ level, leading to increased soot emissions [2]. This was accompanied with an increase in the engine-out emissions of soot. Figure 6 a shows the optical density, $K L$, in the cylinder for three intake $\mathrm{O}_{2}$ levels. As previously mentioned, $K L$ is proportional to the soot volume fraction in the beam path. The curves show a marked late-cycle decay due to soot oxidation. Figure $6 \mathrm{~b}$ shows aethalometer data from the all-metal engine. The curves represent the content of BC in samples drawn from the cylinder at different crank angle positions during the cycle. In both these figures it can be seen that the $21 \% \mathrm{O}_{2}$ data set represents the steepest 
decay and the $13 \% \mathrm{O}_{2}$ case the slowest. The two measurement setups independently show that a global effect of the reduction in inlet $\mathrm{O}_{2}$ concentration is a reduction in the rate of soot oxidation.

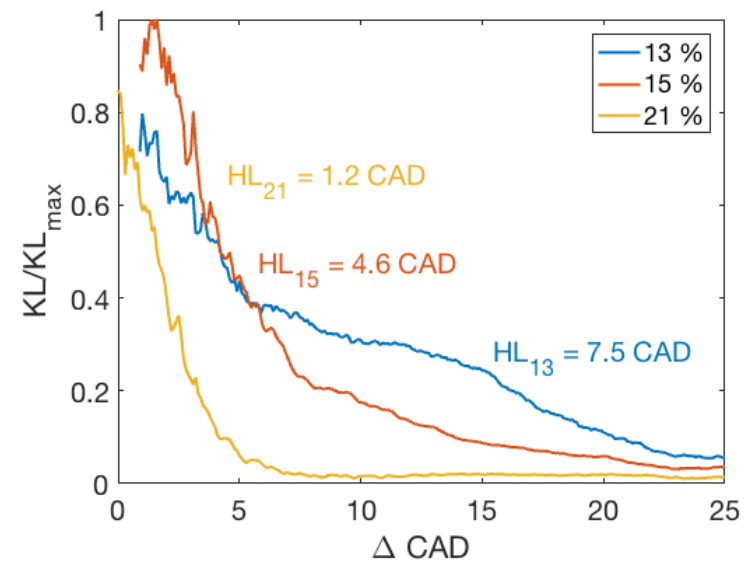

Figure 6a.

Evolution of $K L$ (relative to the peak $K L$ at $15 \% \mathrm{O}_{2}$ ) in the optical measurements shown from the start of decay. The half-life extracted from the exponential approximation is shown in CAD.

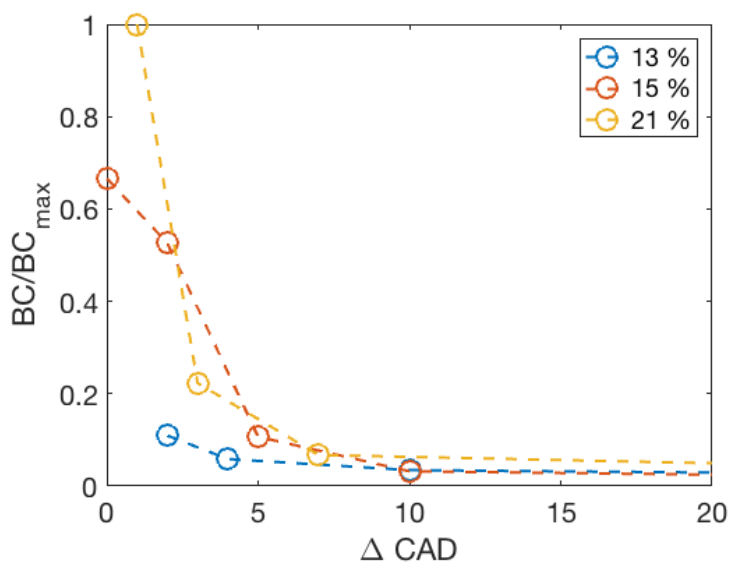

Figure $6 b$.

Evolution of BC from the in-cylinder sampling measurements shown from the start of decay.

There are several potential ways to quantify these soot oxidation rates. One method is to fit an exponential decay function to the extinction curves and extracting the half-life (HL) [2]. 
Although the $13 \% \mathrm{O}_{2}$-case in Figure $6 \mathrm{a}$ is not perfectly described by an exponential (13\% $\mathrm{O}_{2}$ ), the half-lives extracted from the curves still give a useful estimate of the overall oxidation rates. When decreasing the $\mathrm{O}_{2}$ concentration from $21 \%$ to $13 \%$, i.e. by a factor of less than two, the decay rates in Figure 6a display a six-fold increase. This indicates that the availability of $\mathrm{O}_{2}$ in itself is not governing the oxidation rate.

$\mathrm{O}_{2}$ and $\mathrm{OH}$ are both important soot oxidizers [8]. According to Bartok and Sarofim [6], both $\mathrm{OH}$ and $\mathrm{O}_{2}$ play a role under lean conditions while $\mathrm{OH}$ is likely to be dominating under fuelrich and stoichiometric conditions [6]. Since the late-cycle soot oxidation is a mixingcontrolled combustion process, it is expected to take place near stoichiometric conditions, and $\mathrm{OH}$ is thereby expected to be the main soot oxidizer under diesel conditions. About $10-20 \%$ of all $\mathrm{OH}$ collisions with soot are effective at gasifying a carbon atom $[7,10]$. Moreover, Guo et al. have shown that soot oxidation by $\mathrm{OH}$ has negligible activation energy and they point out that, for premixed and diffusion flames, optimized models indicate that soot oxidation by $\mathrm{OH}$ dominates over $\mathrm{O}_{2}[10]$.

While dilution with EGR affects the availability of $\mathrm{O}_{2}$, it has an even greater impact on the flame temperature. The flame temperature, in turn, has a strong effect on the availability of OH. Figure 7 represents $\Phi-T$ maps obtained using the 0-D reactor model. The colored isofields represent the $\mathrm{OH}$ concentration and the white, green and red curves represent the adiabatic flame temperatures at the different $\mathrm{O}_{2}$ concentrations using an initial temperature of $900 \mathrm{~K}$. The maximum adiabatic flame temperature is $2744 \mathrm{~K}$ at $21 \% \mathrm{O}_{2}$, and drops to $2196 \mathrm{~K}$ for the $15 \% \mathrm{O}_{2}$ case. 
Figure 8 shows normalized number densities of $\mathrm{OH}$ extracted from Figure 7, plotted against the soot oxidation half-lives displayed in Figure 6a. Since the soot oxidation is expected to occur at stoichiometric conditions, the $\mathrm{OH}$ mass fractions are extracted at the maximum flame temperature. As expected, the oxidation rate increases with the $\mathrm{OH}$ concentration in the flame. It can be noted that the six-fold decrease in half-life previously mentioned is accompanied by a roughly six-fold increase in $\mathrm{OH}$ availability.

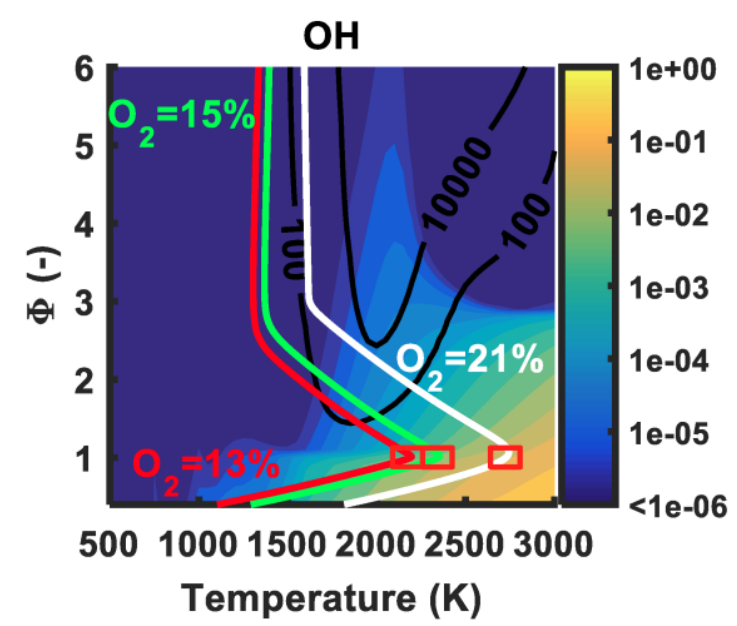

Figure 7.

$\Phi-T$ map of $\mathrm{OH}$ mass fraction constructed using a 0-D reactor with constant pressure, temperature and equivalence ratio. The three red squares highlight the maximum adiabatic flame temperature corresponding to the three cases $\left(13,15\right.$ and $\left.21 \% \mathrm{O}_{2}\right)$. The scale on the right represents the mass fraction of $\mathrm{OH}$ species.

Besides the availability of $\mathrm{OH}$, the local temperature could be expected to affect the soot oxidation rate. In Seidel's mechanism, however, the activation energy for OH-soot reactions is zero, yielding a dependence on $\mathrm{OH}$ concentration and the soot area-to-volume ratio, but not on temperature. This is motivated by $\mathrm{OH}$ being a very reactive species. The current study provides no data on soot morphology but, assuming that the area-to-volume ratio remains 
constant, the temperature dependence of the $\mathrm{OH}$-soot reactions can be estimated using the model of Neoh et al. [29]

$$
\omega_{O H}=\gamma_{O H} \frac{3 n_{O H}}{N_{A}}\left(\frac{8 R T}{\pi M_{O H}}\right)^{1 / 2} .
$$

Here, $\omega_{O H}$ is the soot oxidation rate, $n_{O H}$ and $M_{O H}$ are the number density and the molar mass of $\mathrm{OH}, R$ is the general gas constant and $N_{A}$ is Avogadro's number. $\gamma_{O H}$ is the collisional frequency between $\mathrm{OH}$ and the soot surface and is assigned a value of 0.13 by Neoh et al. [29]. Inserting the $\mathrm{OH}$ concentrations and the peak adiabatic flame temperatures from the simulations into this model yields the oxidation rates presented in Figure 8 alongside the $\mathrm{OH}$ number density. Both the number densities and the rates are normalized to facilitate comparison. Although the temperature drops by $25 \%$, the estimated oxidation rate drops at the same rate as the $\mathrm{OH}$ concentration. This supports both the assumption that the $\mathrm{OH}$-soot reactions are not temperature dependent, and the claim that $\mathrm{OH}$ is the dominant soot oxidizer.

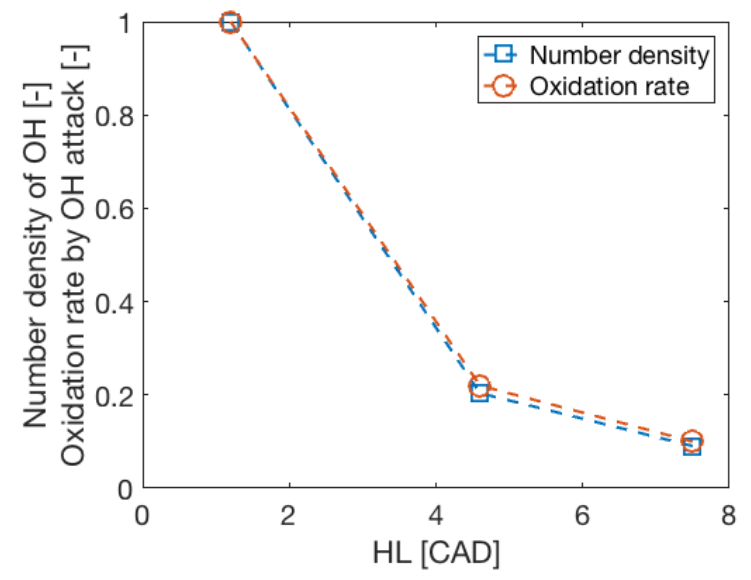

Figure 8.

Variation of the relative number density of $\mathrm{OH}$ (blue curve) and soot oxidation rate according to Neoh et al. [32] (red curve) at the 3 cases studied, versus the variation of the oxidation half-life.

\section{Conclusions}


The in-cylinder soot oxidation slows down when the inlet concentration of $\mathrm{O}_{2}$ is reduced. This observation has been confirmed through measurements using two techniques on two different engine setups. Decreasing the intake $\mathrm{O}_{2}$ concentration by $50 \%$ reduces the soot oxidation rate by $600 \%$. The discrepancy between these numbers indicates that $\mathrm{O}_{2}$ in itself is not the main soot oxidizing species.

The reduction of inlet $\mathrm{O}_{2}$ concentration has a strong impact on the adiabatic flame temperature, and thereby on the mass fraction of $\mathrm{OH}$ during combustion. When the maximum flame temperature drops from $2700 \mathrm{~K}$ to $2400 \mathrm{~K}$, the $\mathrm{OH}$ concentration drops roughly six times. This corresponds well to the drop in the oxidation rate. Both the chemical mechanism used for the $\mathrm{OH}$ simulations and the soot oxidation model by Neoh et al. state that the temperature dependence of the $\mathrm{OH}$-soot oxidation reactions is negligible, due to the high reactivity of $\mathrm{OH}$ radicals. In combination, these findings indicate that $\mathrm{OH}$ is the dominant oxidizer under diesel conditions.

\section{References}

1. Akihama, K., Takatori, Y., Inagaki, K., Sasaki, S. et al., "Mechanism of the Smokeless Rich Diesel Combustion by Reducing Temperature," SAE Technical Paper 2001-010655, 2001, doi:10.4271/2001-01-0655.

2. Gallo, Y., Simonsson, J., Lind, T., Bengtsson, P. et al., "A Study of In-Cylinder Soot Oxidation by Laser Extinction Measurements During an EGR-Sweep in an Optical Diesel Engine," SAE Technical Paper 2015-01-0800, 2015, doi:10.4271/2015-010800 . 
3. Gallo, Y., Li, Z., Richter, M., Andersson, Ö., "A Study of In-Cylinder Soot Oxidation by Laser Extinction Measurements During an EGR-Sweep in an Optical Diesel Engine," SAE Technical Paper 2016-01-2183, 2016, doi:10.4271/2016-01-2183.

4. Aronsson, U., Chartier, C., Andersson, Ö., Egnell, R. et al., "Analysis of the Correlation Between Engine-Out Particulates and Local $\Phi$ in the Lift-Off Region of a Heavy Duty Diesel Engine Using Raman Spectroscopy," SAE Technical Paper 200901-1357, 2009, doi:10.4271/2009-01-1357.

5. Dec, J. and Kelly-Zion, P., "The Effects of Injection Timing and Diluent Addition on Late-Combustion Soot Burnout in a DI Diesel Engine Based on Simultaneous 2-D Imaging of $\mathrm{OH}$ and Soot," SAE Technical Paper 2000-01-0238, 2000, doi:10.4271/2000-01-0238

6. Bartok, W., Sarofim, A.F., "Fossil Fuel Combustion: A Source Book “ New York. Wiley; 1991.

7. Haynes, B.S., Wagner, H.Gg., "Soot formation”, Progress in Energy and Combustion Science, 1981;7:229-273, http://dx.doi.org/10.1016/0360-1285(81)90001-0

8. Tree D.R., Svensson K.I., "Soot processes in compression ignition engines" Progress in Energy and Combustion Science Volume 33, Issue 3, June 2007, Pages 272-309, doi:10.1016/j.pecs.2006.03.002

9. Hayashida, K., Nagaoka, S., Ishitani, H., "Growth and oxidation of graphitic crystallites in soot particles within a laminar diffusion flame”. In: Fuel 128 (2014), pp. 148-154. http://dx.doi.org/10.1016/j.fuel.2014.03.008

10. Guo, H., Anderson, P.M., Sunderland, P.B., “Optimized rate expressions for soot oxidation by OH and 02". In: Fuel 172 (2016), pp. 248-252. http://dx.doi.org/10.1016/j.fuel.2016.01.030 
11. Bowditch, F., "A New Tool for Combustion Research A Quartz Piston Engine," SAE Technical Paper 610002, 1961, doi:10.4271/610002.

12. Hentschel, W. and Richter, J., "Time-Resolved Analysis of Soot Formation and Oxidation in a Direct-Injection Diesel Engine for Different EGR-Rates by an Extinction Method," SAE Technical Paper 952517, 1995, doi:10.4271/952517.

13. Tree, D. and Dec, J., "Extinction Measurements of In-Cylinder Soot Deposition in a Heavy-Duty DI Diesel Engine," SAE Technical Paper 2001-01-1296, 2001, doi:10.4271/2001-01-1296.

14. Mancaruso, E., Merola, S., and Vaglieco, B., "Soot Concentration and Particle Size in a DI CR Diesel Engine by Broadband Scattering and Extinction Measurements," SAE Technical Paper 2005-24-013, 2005, doi:10.4271/2005-24-013.

15. Xu, Y. and Lee, C., "Investigation of Soot Formation in Diesel Combustion Using Forward Illumination Light Extinction (FILE) Technique," SAE Technical Paper 2004-01-1411, 2004, doi:10.4271/2004-01-1411.

16. Cenker, E., Bruneaux, G., Pickett, L., and Schulz, C., "Study of Soot Formation and Oxidation in the Engine Combustion Network (ECN), Spray A: Effects of Ambient Temperature and Oxygen Concentration," SAE Int. J. Engines 6(1):352-365, 2013, doi:10.4271/2013-01-0901.

17. Manin, J., Pickett, L., and Skeen, S., "Two-Color Diffused Back-Illumination Imaging as a Diagnostic for Time-Resolved Soot Measurements in Reacting Sprays," SAE Int. J. Engines 6(4):1908-1921, 2013, doi:10.4271/2013-01-2548.

18. Bohren, C.F and D.R. Huffman, "Absorption and scattering of light by small particles”. 1998, New York, Wiley.

19. F. Migliorini, K. Thomson and G. Smallwood, "Investigation of optical properties of aging soot” Applied Physics B, 2011. 104(2): 273-283. 
20. Shen, M., Malmborg, V., Gallo, Y., Waldheim, B. et al., "Analysis of Soot Particles in the Cylinder of a Heavy Duty Diesel Engine with High EGR," SAE Technical Paper 2015-24-2448, 2015, doi:10.4271/2015-24-2448.

21. Malmborg, V.B., Eriksson, A.C., Shen M., Nilsson, P. et al., "Evolution of in-cylinder diesel soot and emission characteristics investigated with on-line aerosol mass spectrometry", submitted to Journal of Environmental Science \& Technology.

22. Onasch, T.B., Trimborn, A., Fortner, E.C., Jayne, J.T., et al., "Soot Particle Aerosol Mass Spectrometer: Development, Validation, and Initial Application”, Aerosol Science and Technology, 2012, http://dx.doi.org/10.1080/02786826.2012.663948

23. Kamimoto, T. and Bae, M., "High Combustion Temperature for the Reduction of Particulate in Diesel Engines," SAE Technical Paper 880423, 1988, doi: $10.4271 / 880423$

24. LOGE AB. LOGEsoft. http://loge.se/Products/products.html. [accessed 04.09.2016].

25. Lars Seidel et al. "Comprehensive kinetic modeling and experimental study of a fuelrich, premixed n-heptane flame”. In: Combustion and Flame 162.5 (2015), pp. 2045 2058. http://dx.doi.org/10.1016/j.combustflame.2015

26. Wang, X., Song, C., Lu G., Song, J., et al., "Evolution of in-cylinder polycyclic aromatic hydrocarbons in a diesel engine fueled with n-heptane and nheptane/toluene”. In: Fuel 158 (2015), pp. 322-329. http://dx.doi.org/10.1016/j.fuel.2015.05.053

27. Machrafi, H., Cavadias, S., Gilbert, P., "An experimental and numerical analysis of the HCCI auto-ignition process of primary reference fuels, toluene reference fuels and diesel fuel in an engine, varying the engine parameters”. In: Fuel 89 (2008), pp. 10071016. http://dx.doi.org/10.1016/j.fuproc.2008.03.007 
28. Chen, W., Shuai, S., Wang, J., "A soot formation embedded reduced reaction mechanism for diesel surrogate fuel”. In: Fuel 88 (2009), pp. 1927-1936. http://dx.doi.org/10.1016/j.fuel.2009.03.039

29. Neoh, K.G., Howard, J.B., Sarofim A.F. (1974) Effect of oxidation on the physical structure of soot. Proc. Comb. Inst. 20:951 